\title{
Laughter in correction sequences in speech therapy sessions
}

This article deals with the interactional achievement of laughter in speech therapy sessions with adolescents suffering from speech and language impairments. We aim to describe how laughter is locally organized by the adolescent and his/her therapist, and how laughter production provides relevant information about the organization of preference in speech therapy interactions. Using both a conversation analytic approach and quantification, we analyzed video-recorded speech therapy interactions between therapists and adolescent patients in French-speaking Switzerland. We show that adolescents initiate more laughs than therapists overall, but that this pattern is even stronger in correcting contexts, in which such laughs are also predominantly not shared. In correcting activities, the sequential organization of laughter is related to the type of correction trajectory and to the participants' priority in terms of task management. The adolescent produces unilateral standalone laughter when the therapist produces an overt correction, and produces a unilateral laughter-infiltrated second pair-part after the therapist invites him/her to self-correct. By producing unilateral or shared laughter, participants index the importance of correcting business as the main instructional task (unilateral laughter) or as a side activity in the management of an interactional task (shared laughter). Thus, the sequential organization of laughter is not only tied to the asymmetry of institutional status but also to the type of action jointly performed by the participants. By investigating a phenomenon that is still little-known - laughter in therapeutic interactions with dysphasic adolescents - our study provides relevant therapeutic resources for therapists in the collaborative management of a central activity in therapeutic intervention: the business of correction.

Key words: Laughter; Correction; Speech therapy interactions; Adolescents; Conversation Analysis; Quantitative methods

\section{Introduction}

This article deals with communicative functions of laughter in speech therapy sessions with adolescents suffering from speech and language impairments. We propose (1) to study how participants mobilize laughter in speech therapy interactions; (2) to observe at what particular moments participants' laughter is recurrently produced in therapeutic sessions; (3) to better understand why participants laugh in this context.

Conversation analytic studies have shown that laughter is not an uncontrollable reaction to something funny, but a conversational resource that is very precisely organized by conversationalists to achieve many relevant interactional actions, e.g. managing topics (Holt 2010; Bonin et al. 2012), managing turn-taking (Glenn 2010; Ikeda and Bisouth 2013), solving an interactional trouble (Potter and Hepburn 2010; Glenn 2013; Shaw et al. 2013; Petitjean and González-Martínez 2015) and/or displaying (dis)affiliation (Jefferson et al. 1987; Glenn 1995; Holt 2012; Fatigante and Orletti 2013). Concerning the field of speech and language therapy, studies show that laughter may be a very relevant resource that aphasic speakers (Norris and Drumond 1998; Madden et al. 2002; Wilkinson 2007) and autistic children (Auburn and Pollock 2013) use to manage their language disorders while minimizing their impact on the interactional flow. However, to our knowledge, how and why dysphasic adolescents laugh during speech therapy interactions still remain little-known phenomena.

Using a conversation analytic approach (Sacks et al. 1974), we analyzed video-recorded interactions taking place during speech therapy sessions involving one therapist and one adolescent with speech and language disorders (see section 3). Participants' laughter seems to play an important role in a specific type of repair sequence, i.e. correction sequences (see section 4). We also noticed that adolescents laugh more frequently than therapists, and more often in a unilateral way (the therapist does not join in the adolescent's laughter). Previous studies have already shown how aphasic speakers laugh to manage prolonged repair sequences (Wilkinson 2007). Moreover, several studies on laughter in institutional talk have shown that it is a relevant resource for displaying participants' institutional roles: subordinates laugh more than superiors, and subordinates' laughter is mostly not shared (Lavin and Maynard 2001; Haakana 2002). However, these studies do not provide any information about the following points: in speech therapy sessions, do adolescents laugh more often in correction sequences than during other activities? Do adolescents initiate more laughs than therapists (and mostly in a 
unilateral way) because of their respective institutional roles or because of the activity in which they are involved? By performing quantitative analyses (see section 4.2), we show that adolescents initiate more laughs than therapists overall, but that this pattern is even stronger in correcting contexts, in which such laughs are also predominantly not shared. According to these findings, we analyzed adolescents' laughter in correction sequences to understand how and why laughter is unilaterally or jointly produced (see section 4.3). We show that sequential organization of adolescents' laughter depends upon (1) the type of correction (i.e. other- or self-correction); (2) the participants' orientation toward instructional or person-oriented tasks.

Repair trajectories are particularly delicate in contexts in which language impairments are a central issue (Milroy and Perkins 1992; Merrison and Merrison 2005). In speech therapy interactions, repair sequences create opportunities to focus on instructional issues (Ridley et al. 2002; Radford 2008) as they may challenge the linguistic and interactional competence of the patient (Wilkinson 2007), which may trouble the progression of the interaction. By showing how therapists and patients jointly adjust laughter to maximize the instructional value of the repairable while minimizing the problematic features of correction in terms of epistemic positions, our study offers therapeutic resources to help speech therapists develop a greater sensitivity to the functions of adolescents' laughter in speech therapy sessions (see also Petitjean and González-Martínez 2015, on classroom data). This study thus highlights how laughter may be a resource for facilitating therapeutic intervention (see Potter and Goodman 1983; see also Wilkinson 2014 for an overview of "interventionist" CA applied to aphasiology). By focusing on how adolescents with language impairments use laughter to manage interactional difficulties, this study shows that adolescents" "errors" display not only a problem of language performance but above all a sign of interactional competence (see also Jefferson 1974).

\section{Laughter and repair sequences in speech therapy contexts}

\subsection{From repair to correction in talk-in-interaction}

Since repair deals with problems in speaking, hearing or understanding (Schegloff et al. 1977; Schegloff 2007), this is a vital mechanism in the management of talk-in-interaction (Hayashi et al. 2013): by repairing, participants solve troubles that may disrupt mutual understanding and intersubjectivity (Seedhouse 2004). Several studies describe the sequential organization of repair (Schegloff et al. 1977; Hayashi et al. 2013), distinguishing between repair initiation and repair completion. Repair may be initiated by the speaker of the trouble source (self-initiation) or by another participant (other-initiation). In the same way, repair may be completed by the speaker of the trouble source (self-repair) or by another participant (other-repair).

In educational contexts, repair management is mainly linked to instructional tasks (McHoul 1990; Seedhouse 2004; MacBeth 2004) and thus to the business of correction (Jefferson 1987). Correction is viewed as a particular type of repair (Schegloff et al. 1977). Repair deals with the mutual understanding of the ongoing talk, while correction is linked to the appropriateness of the previous reply (Jefferson 1987; MacBeth 2004). However, correction and repair remain co-operating organizations (MacBeth 2004). In classrooms, the teacher may check that he/she has correctly understood the student's answer before beginning a correction sequence that overtly deals with the inappropriateness of this answer (MacBeth 2004; for the link between repair and correction in classroom interactions, see also Hall 2007a and the consequential debate and response papers: Seedhouse 2007; Hall 2007b).

However, even though correction is a kind of repair that is expected in instructional contexts, this is not to say that it is a preferred option. Before producing an other-correction, the teacher provides sequential opportunities to lead students to self-correct (McHoul 1990; Drew 1981 for adult-children interactions; see also Seedhouse 2004 on the link between correction and IRE sequence). When the teacher has to correct the student's answer, he/she avoids an explicit negative evaluation ("no" or "wrong") and initiates a mitigated other-correction (e.g. explaining why the student's answer is incorrect; repeating the incorrect item before providing the correct one; see Seedhouse 2004). Indeed, because correction addresses lapses in the speaker's competence or conduct, participants work to correct with discretion (see Jefferson 1987 on the difference between embedded and exposed 
corrections). In educational contexts, another way of correcting with discretion is to produce selfinitiated other-corrections: the student answers the teacher's question with a rising intonation, asking $\mathrm{him} /$ her to confirm or correct the answer (Seedhouse 2004). Because it is designed as a question, the correction-invitation format (Schegloff et al. 1977; Sacks and Schegloff 1979) allows the teacher to produce his/her correction as an answer projected by the student's question (Seedhouse 2004).

In sum, repair allows conversationalists to make sure that they share a common world (Schegloff 1992) while correction embodies the normative adequacy of a reply (MacBeth 2004). These organizations are particularly interconnected in language therapy interactions: the language disorders that disrupt cross-intelligibility are also the target of the therapeutic intervention.

\subsection{From repair to correction in speech therapy interactions}

Because language disorders may impact mutual understanding, patients with language impairment are particularly exposed to repair (Wilkinson 2007 on aphasic speakers; Radford et al. 2012 on children with specific speech and language disorders). Repair requires a high level of linguistic and pragmatic abilities (Milroy and Perkins 1992), and this thus may be a delicate activity for impaired speakers (see Merrison and Merrison 2005 on children with pragmatic difficulties). Because repair sequences deal with the patient's difficulties, they are particularly useful in terms of therapeutic and/or instructional outputs (Ridley et al. 2002; Radford 2008).

The management of repair trajectories largely depends upon the type of language impairment. Aphasic speakers tend to invite partners to produce other-repairs: the repair trajectory is mostly performed in a "hint and guess" cycle (Milroy and Perkins 1992). Moreover, studies on aphasic talk show that repair is often prolonged compared to ordinary conversation (Milroy and Perkins 1992; Wilkinson 2007). Interestingly, studies in applied conversation analysis show that some repair trajectories may be more helpful for speakers with language impairments, while others are less useful. For instance, the production of known-answer questions by the partner does not systematically help the aphasic speaker to elicit the "correct" answer, and leads to prolonged sequences that disrupt the interactional flow (Wilkinson 2014). Several studies focus on children with specific speech and language difficulties (SSLD) and highlight the link between repair trajectories and learning opportunities. Ridley et al. (2002) show how the institutional status of the unimpaired partner impacts repair trajectories in interactions involving children with SSLD. They show that specialist teachers and peers produce other-repair and other-initiation of self-repair in a way in which the repair provides useful instructional outputs to the impaired partner (see also Radford 2008). Inversely, the mainstream teacher tends not to repair the trouble source, thus minimizing learning opportunities. Existent studies show that children with speech and language impairments may have difficulty in self-correcting: Radford et al. (2012) show that children with SSLD most often self-repair in repair sequences dealing with meaning than in repair sequences focusing on phonological or grammatical forms. With regard to children with pragmatic impairment, Merrinson and Merrinson (2005) show that they rarely initiate repair; however, this study reveals that these children can improve their repair skills when repair management is explicitly taught.

The diversity of repair trajectories allows conversationalists to efficiently manage the various troubles that emerge from their joint actions. In speech therapy contexts, correcting activities may also be a way of resolving speaking, hearing and understanding problems. While repair is the most common and efficient device for dealing with interactional trouble, several studies have highlighted the fact that participants may also mobilize another resource - laughter - to support problem-solving in conversation.

\subsection{Laughter and problem-solving}

Conversation analytic studies show that laughter is a social activity, systematically and sequentially produced in and through talk-in-interaction (cf. Jefferson et al. 1987; Glenn 2003; Vettin and Todt 2004; Glenn and Holt 2013a). By precisely monitoring laughter with regard to its form (number of laugh particles, vowel quality and volume), its deployment in the turn-at-talk (from the beginning of the turn, during and/or after its completion) and its sequential position (volunteered/invited laughter, 
unilateral/shared laughter) (see Glenn and Holt 2013b), participants jointly achieve several social actions (cf. Jefferson 1984, 2010; Glenn 1995, 2003, 2010; Holt 2010; Potter and Hepburn 2010; Hepburn and Varney 2013). Laughter is particularly involved in trouble-solving: managing troublestelling (Jefferson 1984), softening delicate actions (Haakana 2001 in medical encounters; Glenn 2013 for nervous laughter by interviewees in job interviews), managing disagreement (Osvaldsson 2004), indexing the problematic or inappropriate nature of a lexical item (Potter and Hepburn 2010), preempting and solving interactional problems in classroom interactions (Jacknick 2013; Sert 2013; Petitjean and González-Martínez 2015) and displaying problems in delivering a word in secondlanguage-learning interactions (Miyachi 2009).

To our knowledge, only a few studies exist on laughter in speech therapy interactions, and most of them focus on laughter in aphasic talk. Norris and Drumond (1998) highlight the importance of laughter in aphasic communication, showing that laughter appears more often in aphasic than nonaphasic talk. Aphasic speakers laugh more often to initiate talk and keep the floor, and this may explain why aphasic speakers produce more prolonged laughter than non-aphasic speakers. Moreover, aphasic speakers laugh more than non-aphasic speakers when protesting or rejecting the previous talk; this may be explained by the fact that aphasic speakers have to initiate repair more frequently to manage the impact of their language impairment on the partners' understanding. Madden et al. (2002) show how aphasic speakers organize laughter to support conversation and conclude that laughter identifies aphasic speakers as competent interactional partners: laughter has a compensatory function in aphasic talk, allowing aphasic speakers to maintain or repair conversational flow. Wilkinson (2007) focuses on the role of laughter in prolonged repair sequences in aphasic talk. The aphasic speaker may laugh when he/she does not manage to complete the self-repair, despite prolonged efforts to solve the problem. In this case, the partner does not laugh but intervenes in the repair sequence. By laughing, the aphasic speaker minimizes the embarrassing nature of the failed self-repair (on embarrassed laughter, see Goffman 1956; Adelswärd 1989) while providing the partner with an opportunity to complete it.

Laughter allows speakers with language impairments to feel more competent and facilitates their participation in everyday interactions (Madden et al. 2002; Wilkinson 2007; Auburn and Pollock 2013). By laughing, speakers promote progressivity of interaction in spite of their language impairments. In this sense, laughter is a very relevant resource for improving therapeutic strategies (Norris and Drumond 1998). According to Potter and Goodman (1983), laughter is a therapy facilitator. However, to our knowledge, little attention has been paid to the role of laughter in interactions with dysphasic adolescents.

In sum, although several studies exist on repair in interactions with dysphasic children and on laughter in aphasic talk, laughter in repair sequences with dysphasic adolescents is still a little-known phenomenon, particularly in face-to-face interactions with speech therapists. In the following, we will show how and why adolescents and therapists jointly manage laughter in the management of correction sequences in speech therapy sessions.

\section{Data and methodology}

\subsection{Data}

This study is based on a corpus of speech therapy interactions between therapists and adolescent patients in French-speaking Switzerland (IC-You project, Swiss National Science Foundation grant no. CRSII1_136291/1). We worked with two dyads, each composed of an adolescent and a therapist. The two adolescents had been treated for speech and language disorders since they were small children. The first adolescent (Mathieu, ${ }^{1}$ Mat in the transcript) was 16 years old at the time of our study. According to his therapist, Mathieu was a dysphasic speaker with autistic symptoms. He also had pragmatic troubles and writing difficulties. The other adolescent (Barbara, Bar in the transcript) was 14 years old. According to her therapist, Barbara suffered from dyslexia and dysorthographia. She also suffered from deficiency in spoken language, which often generates misunderstandings. The two

\footnotetext{
${ }^{1}$ The first names have been changed.
} 
therapists (Log in the transcript) had been working in speech therapy institutions for many years. We analyzed two sessions for each dyad, representing a total of three hours of recordings. Each session lasted about 45 minutes and was held in the therapist's office.

We compiled a collection of 118 excerpts including participants' volunteered laughter. We refined the transcriptions of these excerpts to precisely identify the sequential position of laughs and smiles (see Hepburn and Varney 2013 on laughter transcription). We used the symbol $£$ to delimit segments produced with a smile voice. Furthermore, we transcribed bodily behavior, in particular smiling, using the norms proposed by Petitjean and González-Martínez (2015): the \# symbol indicates when bodily actions begin and finish during the speaker's turn (superscript is used to distinguish simultaneous bodily behavior). The line below the speaker's turn (in italics) indicates the person performing the action and its type. Here is an illustration, extracted from excerpt 3 (see section 4.3.1.1):

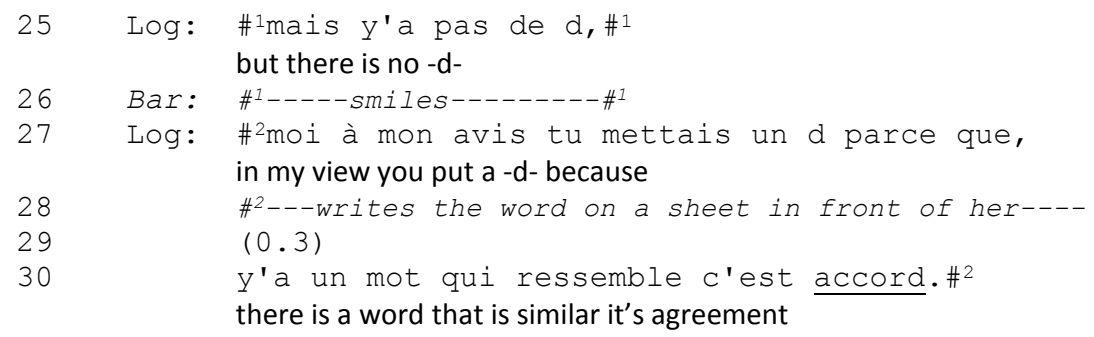

Barbara begins to smile (26) as her therapist begins to talk (25), as indicated by the symbols $\#^{1}$ at the beginning of lines 25 and 26. Barbara stops smiling at the end of the therapist's turn-constructional unit, as indicated by the symbols $\#^{1}$ at the end of lines 25 and 26 . The therapist begins to write on a sheet of paper (28) while she initiates the next turn-constructional unit in line 27 (as indicated by the symbol $\#^{2}$ at the beginning of lines 27 and 28), and keeps writing until the end of her turn, as indicated by the symbol $\#^{2}$ at the end of line 30 . More generally, our transcripts are based on Jeffersonian conventions (Jefferson 2004).

\subsection{Methodology}

We analyzed our data using both qualitative and quantitative methods (on mixed-approach applied to interactional data, see Heritage et al. 2007; Rossano et al. 2009; Wilkinson 2014; see also Stivers 2015, Steensig and Heinemann 2015 for a discussion on CA-grounded formal coding approach). Following a conversation analytic approach (Sacks et al. 1974), we focused on the participant who laughs first (adolescent or therapist), the position of laughs in the sequences (unilateral vs. shared laugh) and in the turns at talk (standalone laughter, laughing-turn). Quantitative and statistical analyses acted as intermediaries between the two steps of the conversational analyses: first, they were used to confirm the observations resulting from our data collection (i.e. adolescents initiate more laughs than therapists; this pattern is even stronger in correcting contexts, in which such laughs are also predominantly not shared). Secondly, these findings lead us to focus on the sequence type in which laughter is recurrently involved (i.e. correction sequence), which we then sequentially analyzed to describe the communicative functions of laughter, according to whether it is jointly produced with the therapist or not.

Quantification in conversation analytic studies is challenging (Schegloff 1993; Haakana 2002; Heritage et al. 2007; De Ruiter to appear). The analyst has to precisely determine what "object" may be quantified from the interactions he/she analyzes. Counting occurrences of an interactional object $x$ in a corpus is not informative enough, since it ignores how and when this object should (or should not) appear in the interactional flow, which Schegloff $(1993,103)$ calls an environment of possible relevant occurrence. Counting an object $x$ when it accomplishes a function $y$ is also problematic, since functions should be assessed as outcomes of the analysis, rather than as their starting point. Moreover, there is a "many-to-many" mapping between functions and resources: a given function may be accomplished through different conversational resources, and inversely. Schegloff (1993) highlights another problem in quantification based on interactional data: quantification needs to define a domain in which an object can be counted. Yet, in studies on talk-in-interaction, this domain (or context/situation) cannot be defined in itself: by co-adapting their conversational methods, participants 
themselves build and display the context in which they are acting (e.g. ordinary conversation, medical encounter, interviews, etc.; see Schegloff 1993). Moreover, while quantification aims to underscore recurrences in the conversationalists' practices, it is not meant to elucidate how conversationalists jointly build social action and meaning; only a sequential analysis can reveal this. For all these reasons, quantification should not be an alternative to sequential analyses, but rather should stem from them (see also Heritage et al. 2007). In studies on talk-in-interaction, the aim of a quantitative approach is not to flatten out the complexity of social action by generalizing interactional phenomena (i.e. saying that conversationalists always act in the same way when they are in the same context). The point is rather to tell frequent or expected behavior from infrequent or unexpected behavior, thus indicating which phenomena require further qualitative analyses. This practice echoes Steensig and Heinemann's (2015, p.23) view of coding "as a process that opens up to new angles and new qualitative studies and not as an end result".

In this study, quantification is based on an initial qualitative analysis of the dataset, which leads us to a collection of cases in which participants initiate laughter. Our collections show that laughter frequently appears in correction sequences. We did not count all the laugh particles in the interactions we analyzed (see the problem of denominator in Schegloff 1993), and neither did we count laughs according to their communicative functions (see the problem of numerator in Schegloff 1993). Instead, we counted laughter when initiated in correction sequences, that is, the number of laughs initiated by the adolescent and the number initiated by the therapist, according to their sequential organization (for more details, see sections 4.1 and 4.2).

\section{Data analyses}

In the speech therapy interactions we analyzed, laughter seems to be particularly involved in the business of correcting (see section 4.1). This is confirmed by quantitative analyses (see section 4.2), which also show that laughter in correction sequences is mostly initiated by the adolescent in a unilateral way. Moreover, we show that this sequential organization (adolescents' laugh-initiation; unilateral laughter) is not only linked to the participants' institutional roles (adolescent vs. therapist) but also to the interactional activity in which they are involved (correction sequence vs. non-correction sequence). Based on micro-analyses of laughter in the correction sequences of our corpus (see section 4.3), we show that sequential organization of adolescents' laughter (standalone vs. turn-infiltrated laughter; unilateral vs. shared laughter) is mainly linked to the type of correction (i.e. other- or selfcorrection) and to the participants' orientation toward instructional or person-oriented tasks.

\subsection{Correction as a laughing activity in speech therapy sessions?}

In the speech therapy sessions we analyzed, the adolescents frequently laugh when they are involved in correcting activities. In this case, laughter is mostly initiated by the patient without being shared with the therapist, as in the following excerpt. The therapist is helping Mathieu correct spellings in a word list. Mathieu has made an error when spelling the word discothèque (Engl. night club): he has used the acute accent instead of the grave one.

Ex.1 - MA(1) Night club 


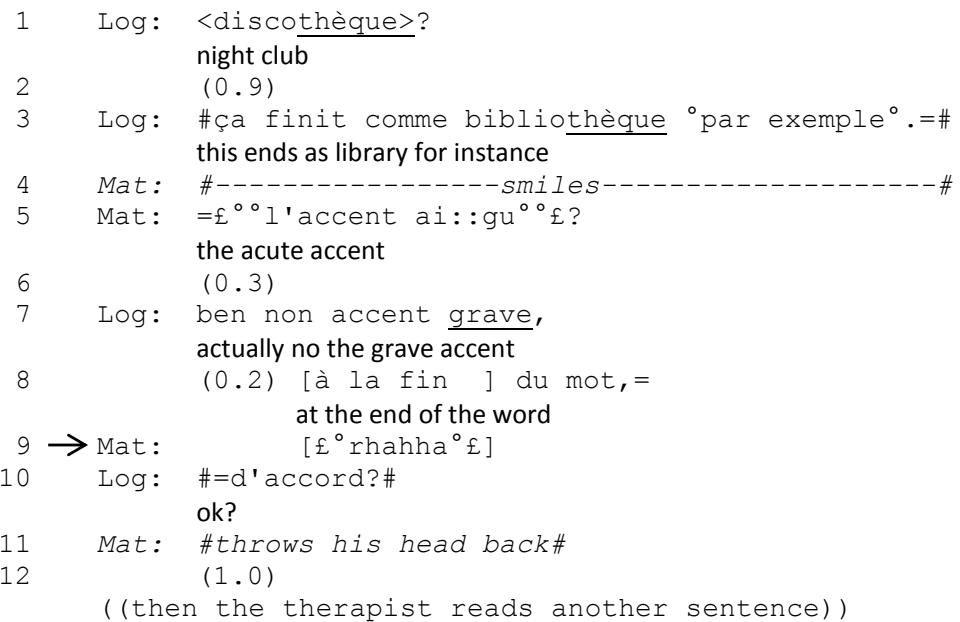

Mathieu responds to the therapist's other-initiations of self-correction (1-3) with a self-initiation of other-correction (see the rising intonation in line 5). The therapist explicitly assesses Mathieu's answer as wrong (actually no, 7) before giving the right answer (7-8). Mathieu laughs during the last part of the therapist's turn without confirming or rejecting the correction (9). The therapist closes the sequence without laughing herself: she produces a confirmation check (10) before continuing the exercise.

This laughter organization seems to be common in the interactions of our corpus. To evaluate the commonness of this pattern, we performed quantitative analyses of participants' laughter. We collected all the sequences in which a participant initiates laughter $(n=118)$. We counted all the correction sequences during which a participant (adolescent or therapist) initiates laughter $(n=74)$. We then counted the cases in which the laughter is initiated by Barbara, Mathieu, Barbara's therapist and Mathieu's therapist, depending on the session (session 1 vs. session 2). For each participant and each session, we counted the number of cases in which laughter-initiation leads to a unilateral or shared laughter. The same was done for the remaining laughter sequences (i.e. sequences that do not deal with correcting activities).

\subsection{Participants' laughter quantification}

Counts of laughs are shown in Table 1, split by Participant (Patient vs. Therapist) and nested Individuals (Barbara, Mathieu, Barbara's therapist, Mathieu's therapist) and Session (S1 vs. S2) in rows, and by Context (Repair vs. Other ${ }^{2}$ ) and nested Type (Unilateral vs. Shared laughter) in columns. Given the restricted number of observations and the similarity of the numeric trends, in the quantitative analysis counts are pooled across Individuals and Sessions, and Type analysis is restricted to Patients.

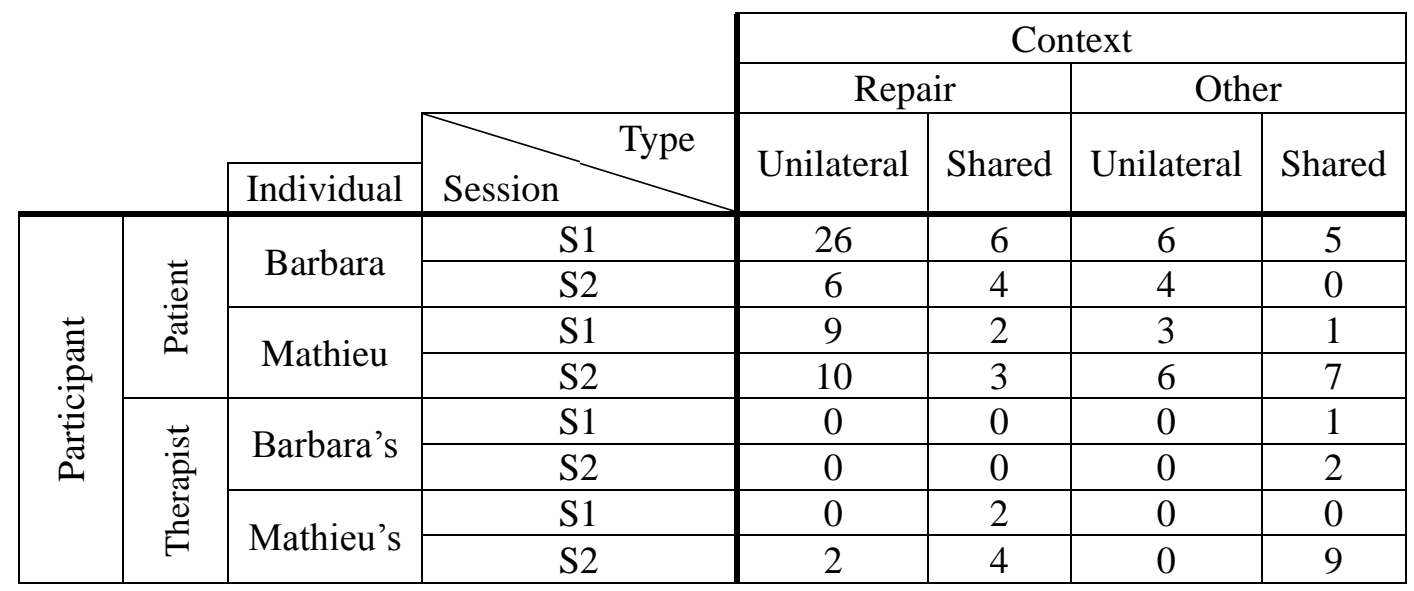

\footnotetext{
${ }^{2}$ This category corresponds to sequential contexts that do not deal with repair.
} 
As for the distribution across Participants, a two-tailed exact binomial test for goodness-of-fit supports the hypothesis of Patients initiating more laughs than Therapists, independent of Context (98 vs. 20; $<$ 0.001). The effect holds when evaluating Contexts independently, with Patients initiating more laughs than Therapists both in Repair contexts (66 vs. 8; $\mathrm{p}<0.001)$ and in Other contexts (32 vs. 12; $\mathrm{p}<0.01$ ). If Participants are evaluated independently, we find that Patients initiate more laughs in Repair than in Other contexts (66 vs. 32; $\mathrm{p}<0.001)$, while Therapists do not. Therapists actually show the opposite trend ( 8 vs. $12 ; \mathrm{p}=0.5$ ), which however does not reach significance. This is confirmed by a Chi-Square test of independence, showing that Participant and Context are related $\left(\chi^{2}(1)=5.3\right.$, $\mathrm{p}=0.02$ ). Figure 1 (left panel) provides a synthetic visualization of all the findings mentioned above.
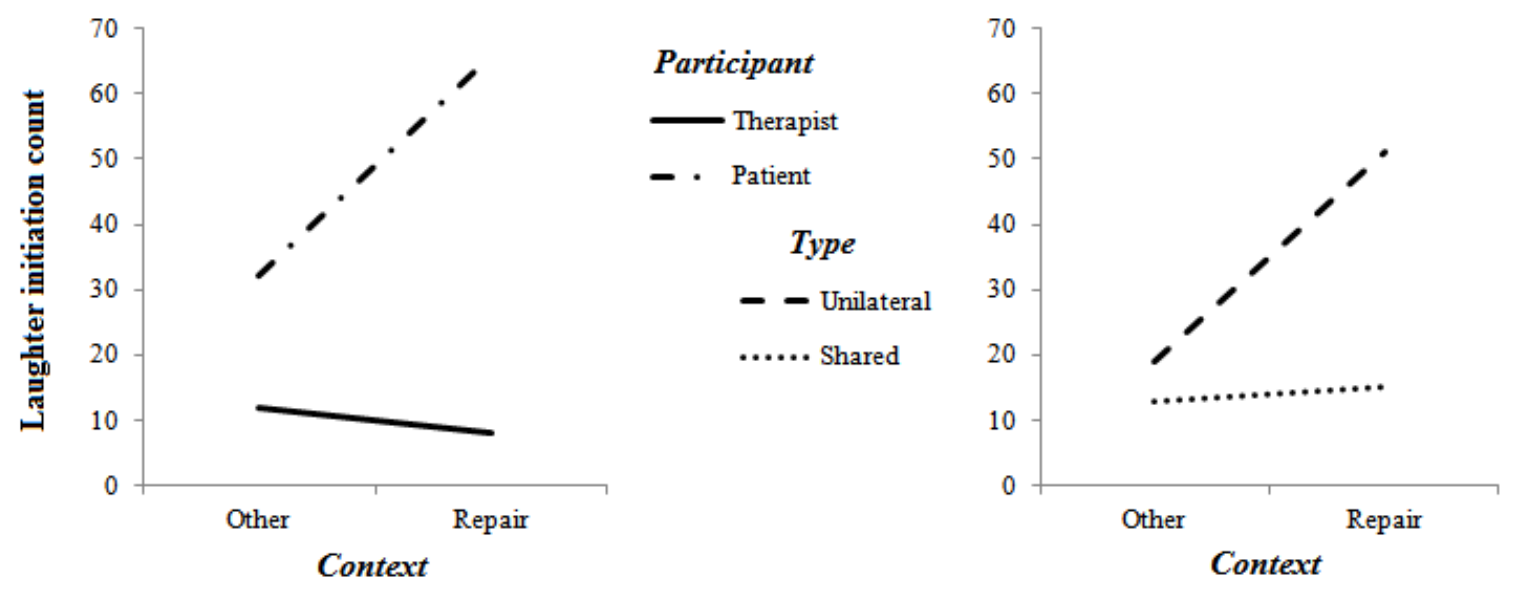

Fig. 1 - Laughter initiation counts (y-axis) as a function of Context (Other vs. Repair, xaxis). Counts are split by Participant (Patient vs. Therapist) in the left panel. Counts for

Patient-initiated laughter are split by Type (Unilateral vs. Shared) in the right panel.

As for the distribution across Types (Unilateral vs. Shared), limiting ourselves to laughs initiated by Patients, a two-tailed exact binomial test for goodness-of-fit supports the hypothesis of Patients initiating more Unilateral than Shared laughs independent of Context (70 vs. 28; p <0.001). A ChiSquare test of independence suggests, however, that this effect might be mediated by the interaction between Type and Context $\left(\chi^{2}(1)=3.3, \mathrm{p}=0.06\right)$. This is confirmed by further exact binomial tests showing that Patients initiate more Unilateral than Shared laughs in Repair contexts (51 vs. 15; $\mathrm{p}<0.001$ ), but not in Other contexts ( 19 vs. $13 ; \mathrm{p}=0.37$ ). These findings are synthetically visualized in Figure 1 (right panel).

Taken together, the findings above indicate that Patients initiate more laughs than Therapists overall, but that this pattern is stronger in Repair contexts, in which such laughs are also predominantly not Shared.

In the following section, we will describe the sequential organizations of unilateral and shared laughter initiated by the adolescents in order to understand how laughter management affects correction trajectories and why therapists sometimes laugh, but not always.

\subsection{Sequential organizations of adolescents' laughter in correction sequences: why do therapists sometimes laugh (but not always)?}

In the speech therapy sessions we analyzed, adolescents suffering from speech and language impairments largely use laughter when they are involved in correction sequences. After the adolescent 
laughs in a correction sequence, the therapist sometimes laughs, but not always. In the following section, we will describe these two sequential patterns.

\subsubsection{Adolescents' unilateral laughter}

In most cases, the adolescents produce unilateral laughter in correction sequences. Below we will focus on the form of adolescents' laughter and its sequential positions according to the type of correction trajectory: (1) when the therapist produces an overt correction; (2) when the therapist invites the adolescent to self-correct.

\subsubsection{Adolescents' unilateral laughter after therapists' other-correction}

In excerpt 1 (see section 4.1), the adolescent laughs after the therapist produces an overt correction (no the grave accent, 7); Mathieu's turn is composed only of laugh particles, without speech. The therapist does not join in Mathieu's laughter.

We observe the same organization in the following excerpt. Barbara is doing an exercise on her computer: she has to write words dictated by the software. The therapist sits next to Barbara and checks her answers. Here, the target word dictated by the computer is the word partout (Engl. everywhere; see line 1). Earlier in the session, the software had already dictated this word; Barbara had made a mistake that she had corrected with the help of the therapist.

Ex. 2 - BA(1) Everywhere 


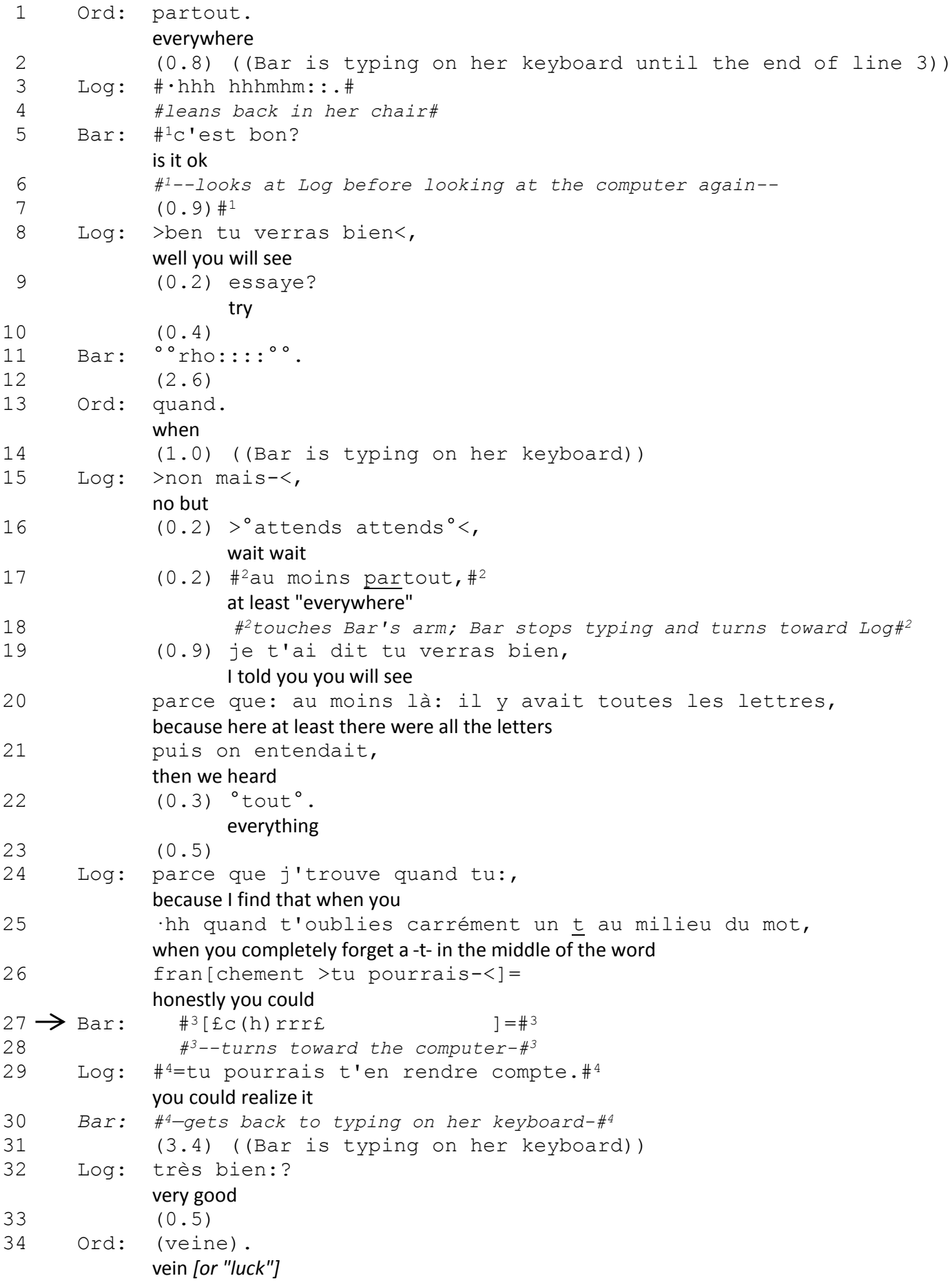

Barbara has to manage a delicate moment in terms of epistemic status (see Heritage 2012 on epistemic management): she shows difficulty in correctly spelling an item that she has already typed earlier in the session, resulting in a prolonged correction sequence that leads Barbara to display a lack of epistemic access. While Barbara is typing the answer (2), the therapist sighs (3) and leans back in her chair, displaying that Barbara's answer is unsatisfying. This is interpreted as such by Barbara, who asks the therapist to confirm her candidate answer, displaying an uncertain epistemic stance (5). The therapist disaligns with Barbara by inviting her to check whether the answer is validated by the computer or not (8-9; see also in line 7 the turn-initial delay as announcing a dispreferred action, Jefferson 1974; Schegloff 2007). Barbara discreetly expresses her disappointment (11) while not modifying the answer. The software evaluates the answer $(12)^{3}$ before moving on to another target

\footnotetext{
${ }^{3}$ After the software dictates a target word, the user has a predefined amount of time for answering. When the
} 
word (13). Barbara begins to answer (14) but the therapist suspends the ongoing activity: she produces an overt disagreement (15; see the no-token in turn-initial position) before prompting Barbara to wait (16). She then identifies the trouble source (17), which concerns the previous target word (everywhere). In line 19, the therapist explains why she did not satisfy the self-initiated othercorrection that Barbara oriented to in line 5, arguing that the grapheme-phoneme correspondence was clear enough (20-22). The therapist thus shows that Barbara's previous answer was not correct as she provides Barbara with an opportunity to self-correct (see the silence in line 23; see also Drew 1981; McHoul 1990; Seedhouse 2004 on how an explanation can function as a way of providing the partner with an opportunity to self-repair). Since Barbara does not self-select, the therapist takes the floor again and produces an other-correction by identifying Barbara's mistake (i.e. she has forgotten the letter - $\mathrm{t}$ - in the middle of the word partout, 24-25). Interestingly, it is just after the therapist performs the correction that Barbara produces a standalone laugh (27), in overlap with the therapist, who is challenging Barbara's skills (you could realize it, lines 26 and 29). By laughing at her mistake, Barbara shows that she takes it lightly. She retroactively downgrades the seriousness - or the relevance - of the error $^{4}$ while modulating its embarrassing nature in terms of epistemic access (Seedhouse 2004; Sert and Jacknick 2015). Moreover, by laughing without speaking, Barbara responds to the therapist's other-correction but without elaborating on it: by not producing acknowledgements, apologies and/or a repetition of the corrected item, which are the usual sequential implications after a correction (see Drew 1981; Sidnell 2010), Barbara makes the error less focusable (see Mazeland 1987 on the "focusability" of a repairable). By not laughing, the therapist does not affiliate with the adolescent's stance, displaying unwillingness to minimize the problematic nature of the mistake.

The same pattern is observable in the following excerpt. Barbara and her therapist are doing the same exercise on the computer. Just before this excerpt, the software has dictated the target word encore (Engl. again). Barbara has displayed difficulty in spelling the item: she has written encodre, adding the letter - $\mathrm{d}$ - in the middle of the word. The therapist thus helps her to find the correct answer by focusing on the word's pronunciation (1-2).

Ex. 3 - BA(1) Again

time has run out, the software indicates whether the answer is right or wrong before moving on to another target word. Unfortunately, since we cannot see the computer's screen on the video, we do not know what Barbara is writing and whether her answer is accepted or rejected by the software.

${ }^{4}$ The notion of "seriousness" has been widely discussed in conversation analytical literature. A turn is designed or interpreted as non-serious when it does not have the usual sequential implications it would have if it has been considered serious (Glenn 1991; Holt 2013). Holt (2013) shows that a participant can laugh in response to a turn that is designed to be serious, as a way of treating the previous turn as not having its usual sequential implications, which may be particularly useful for managing delicate moments. In our data, we find a similar pattern: by laughing, Barbara does not satisfy the serious sequential implications expected after a correction (i.e. producing acknowledgment, apologies, or disagreement) and thus retroactively downgrades the seriousness of the therapist's other-correction. However, we prefer to talk about the "seriousness of the trouble" (or of the mistake) rather than the "seriousness of the previous turn at talk" in the sense that Barbara does not work only to minimize the therapist's other-correction but mainly to minimize her own error, which has led to the correction. 


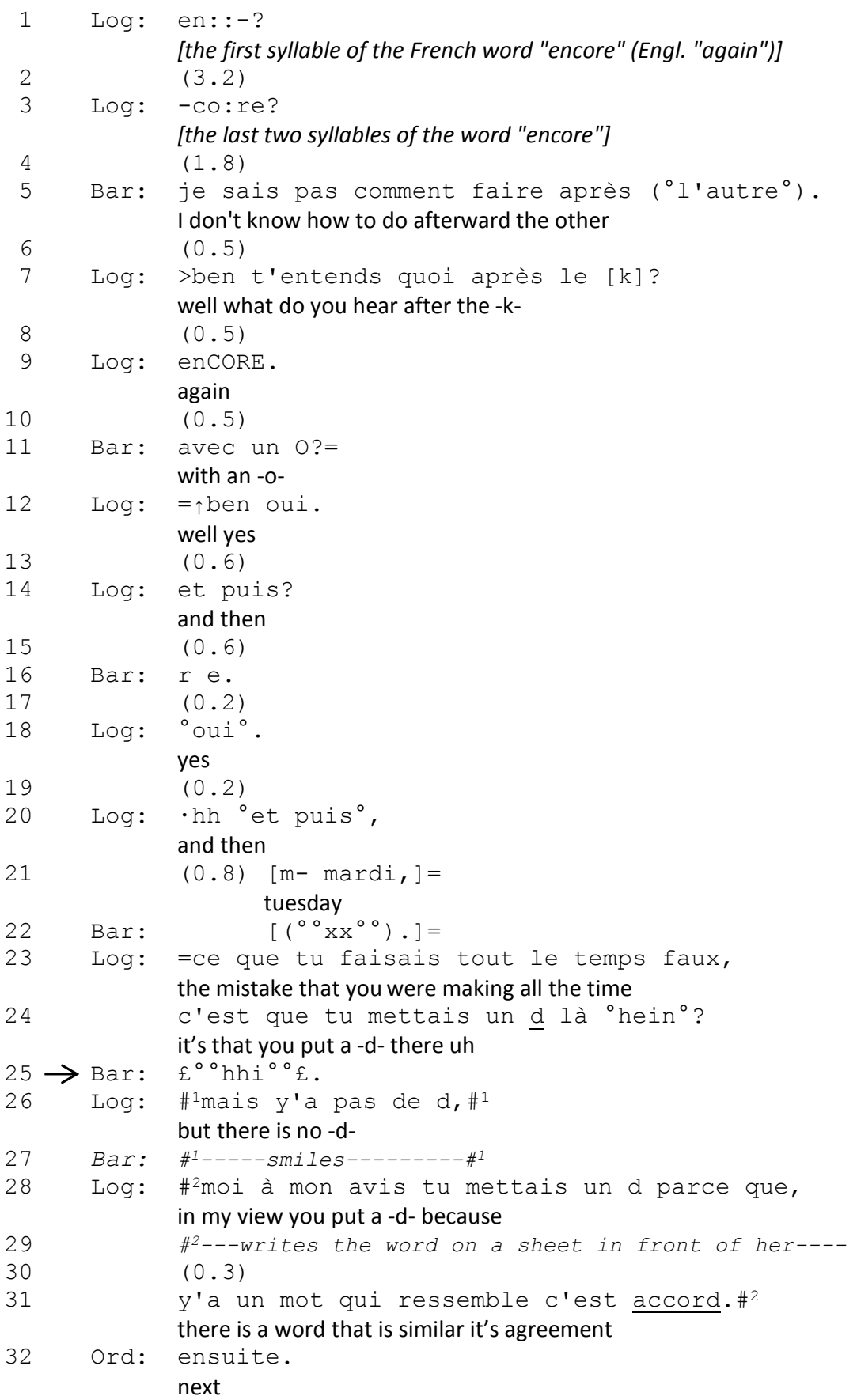

Barbara and her therapist are involved in a prolonged correction sequence. Barbara displays difficulty in finding the correct spelling of the target word. Although the therapist's designedly incomplete utterance (Koshik 2002) solicits an answer from Barbara (1), she does not respond (2). The therapist then provides a phonetic clue (3), to which Barbara responds (5) by producing a claim of insufficient knowledge (Sert and Walsh 2013). The therapist offers Barbara an opportunity to self-correct (7) before giving her another phonetic clue (9). Barbara responds by inviting the therapist to correct her answer (see the rising intonation in line 11). The therapist approves Barbara's answer (12) before inviting her to continue (14). After Barbara succeeds in finding the correct spelling (16-18), the therapist returns to Barbara's mistake and produces a mitigated other-correction (20-24): she explicitly points out the error (you put a-d-here but there is no - $d$-, lines 24 and 26), but does this in a way that displays the error as made the week before (and not as the initiator of the ongoing correction sequence) $(21,23)$. Here too, Barbara produces a discreet standalone laugh (25) and smiles (27) during the therapist's correction. The therapist does not join in Barbara's laughter: she remains focused on the correcting activity, providing explanation of how the error was caused (28-31). 
According to these analyses, the adolescents produce standalone laughter during or after the therapists' other-correction: by laughing without speaking, the adolescents respond to the correction while displaying passive recipiency (see Ikeda and Bysouth 2013 on the link between laughter and turntaking). By responding, they avoid disalignment with the therapist; by laughing at the mistake, they reassert their epistemic position by displaying their lack of epistemic access as not so serious; and by laughing without speaking, they avoid elaborating on the therapist's correction, thus making the error less focusable. By not joining in the adolescents' laughter, the therapists remain focused on the relevance of the correcting activity that they promote as the primary instructional task. The therapist produces a confirmation check (ex.1), reproaches the partner (ex.2), and provides explanation (ex.3) before continuing the exercise (exx.1-3).

\subsubsection{Adolescents' unilateral laughter after therapists' other-initiation of self-correction}

In excerpt 4, the therapist asks Mathieu how much time they have left (1) in order to select the appropriate activity to do before the end of the session.

Ex. 4 - MA(2) How much time 
Log: \#alors on a: combien de: temps: :?\#

so how much time do we have

\#--Log and Mat are looking at the clock on the wall---\#

$(0.6)$

Mat: $\quad\left(>^{\circ}\right.$ euh ben $\left.^{\circ}<\right)$,

uh well

(0.3) \#il est: et qua: :tre,\#

it is "and four"

(1.5) euh: : : ,

$(0.4)<$ neuf minutes $>$ ?

nine minutes

$(0.4)$

Mat: \#neuf à dix minutes?\#

nine or ten minutes

\#--turns toward Log--\#

(0.8)

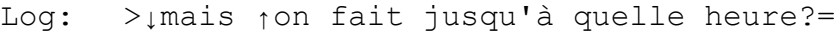
but we stay until what time

Mat: =jusqu'à et quart. until "and a quarter"

(0.3)

Log: \#donc ça fait combien?\#

so how much is that

Mat: \#-Mat looks at the clock-\#

(0.4)

Log: de: et quatre à: : et qua:rt. from "and four" to "and a quarter"

(3.9)

Mat: $\quad \#^{\circ}$ neuf minutes ${ }^{\circ}$ ?\#

nine minutes

\#turns toward Log\#

$(0.5)$

Mat: $\#^{\circ \circ}$ à peu près ${ }^{\circ}$. \#

more or less

Log: \#shakes her head no while showing her teeth\# $(0.7)$

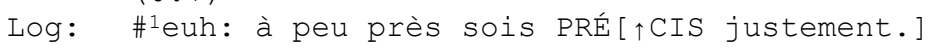
uh more or less be precise actually

\section{$\#^{2}[£ h h$ HOHon \\ ] ${ }^{\circ}$ hohoh}

$\#^{2}$ shifts his position to face away from Log, looking downward, then turns back and looks at Log \#2

$(0.7)$

Log: \#3alors et [quart $s:-$, ] so "and a quarter"

Mat: \#3-balances on his chair--

Mat: [£dix plus unf.]

$(0.4)$

$$
\text { ten plus one }
$$

Mat: $\quad$ fon $[z e £$.

eleven

Log: $\quad[$ eh: : . ]

$(0.7)$

Mat: $£^{\circ} \circ \operatorname{one}^{\circ} £ .=$

eleven

Log: =mathieu: :

(0.1) >attention< d'pas tomber, $\#^{1} \#^{3}$

be careful not to fall

à et quart ça fait combien de minutes?

to "and a quarter" how many minutes is that

(3.1)

Mat: ${ }^{\circ}$ euh: onze ${ }^{\circ}$.

uh eleven 
In this excerpt, Mathieu is involved in a problematic episode. He displays difficulty in answering, leading the therapist to produce several invitations to self-correct. Mathieu delivers his answer tentatively: he produces turn-initial delays $(3,5,7$ and 8$)$, hesitation markers $(4,7)$ and withholds his answer by mobilizing data of the math problem that he needs to resolve (it's and four, 5$)^{5}$. Moreover, Mathieu designs his answer as an invitation for the therapist to produce an other-correction (see the rising intonation and the faster speech rate in line 8), casting doubt on its correctness. Since the therapist neither confirms nor rejects the answer (9), Mathieu provides another candidate answer (10) which is less precise than the previous one (nine or ten minutes), again seeking confirmation from the therapist (see the rising intonation). Here too, the therapist does not correct Mathieu's answer; instead, she helps Mathieu to self-correct by formulating the successive steps of the problem solving $(13,16$ and 19; see also Mazeland 1987 on how teachers lead students to self-correct by explaining how to make the correction). In line 21, Mathieu recycles his previous answer, here too in a way that invites the therapist to make an other-correction. Since the therapist remains silent (23), he takes the floor again (24) and mitigates his previous answer (more or less) with a very low voice. The therapist gesturally rejects Mathieu's approximation (25) before overtly inviting Mathieu to self-correct (27), that is, to provide a precise answer. At this point, Mathieu begins to smile (28) before producing a laughing turn (29) that is performed as follows: he first produces laugh particles before self-correcting (ten) and correcting his self-correction (no) with a smile voice. By laughing and smiling in his responsive turn, Mathieu aligns with the therapist while displaying uncertainty regarding the correctness of his answer. By laughing, Mathieu takes advantage of the fact that "a fault confessed is half redressed" (see also Petitjean \& González-Martínez 2015 on classroom data) while inviting the therapist to consider his self-correction as not really serious, thus minimizing opportunity for the therapist to produce an overt correction (see Mazeland 1987 on how teachers' corrections stem from students' unsuccessful attempts to self-correct). And, indeed, the therapist does not correct Mathieu's answer; rather, she resets her supportive strategy (32) but without joining in Mathieu's laughter. By not laughing, the therapist remains focused on the correction activity, which continues for several turns at talk (32-44).

We observe the same organization in the following excerpt. Mathieu and his therapist are talking about spelling issues. The therapist asks Mathieu to list the topics that are linked to spelling in French. Mathieu suggests agreements and conjugation as candidate answers. The therapist prompts him to make other suggestions.

\footnotetext{
${ }^{5}$ In French, the wording "and (number)" is commonly used for indicating minutes when the hour is already known by all the participants.
} 


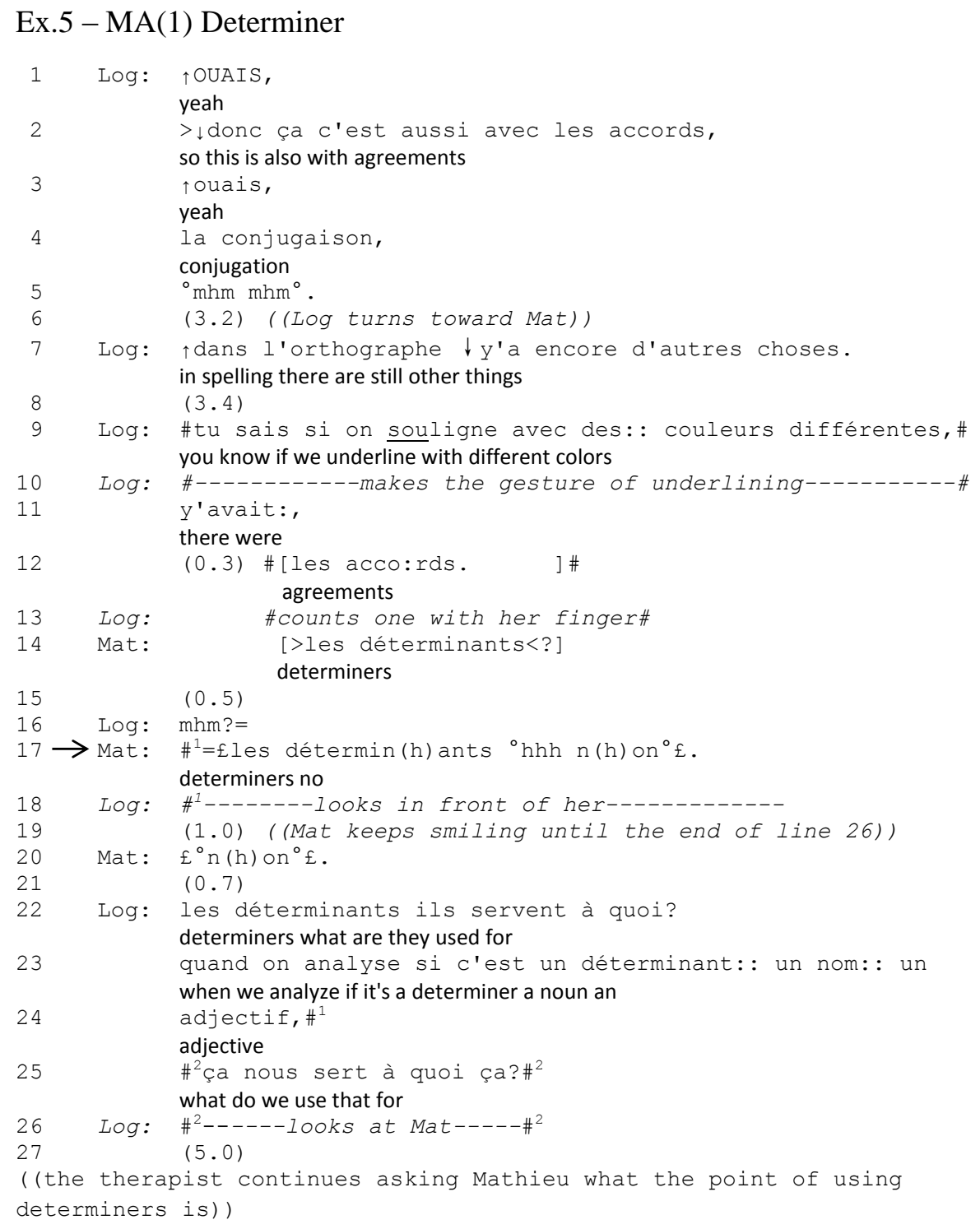

Mathieu has to manage a problematic moment: he has difficulties answering the therapist's question. He does not take the floor when the therapist selects him as the next speaker $(5,7)$, generating silent slots $(6,8)$. Inversely, in line 14, he delivers a candidate answer (determiners; see the rising intonation and the faster speech rate) before the therapist has finished her turn (see the non-final intonation in line 11), causing an overlap that leads the therapist to produce a repair-request (16). At this point, Mathieu's turn shape shows that he interprets the therapist's repair-initiation as an invitation to selfcorrect $^{6}(17)$. Indeed, he laughs while repeating his previous answer, displaying uncertainty with regard to the correctness of his answer before rejecting it (no, 20). By producing a laughing responsive turn, Mathieu satisfies the sequential expectations of what he himself considers as an invitation to selfcorrect while designing his self-correction as not really serious, thus limiting the opportunity for the therapist to perform an overt negative evaluation of his error. And, indeed, while the therapist does not join in Mathieu's laughter, remaining focused on the instructional task, she does not overtly correct Mathieu's answer; instead, she provides Mathieu with a new opportunity to self-correct (22-26).

\footnotetext{
${ }^{6}$ Note here that the way in which Mathieu interprets the therapist's repair-initiation adheres to what has been shown by conversation analytical studies: a problem of acceptability is first addressed as a hearing problem (Schegloff 2007; Svennevig 2008). Moreover, we do not have access to the cause of the problem displayed by the therapist (problem of hearing or of acceptability), but only to how the partner interprets the nature of the trouble (Svennevig 2008). And, here, Mathieu clearly orients toward a problem of correctness.
} 
In the following excerpt, the adolescent also produces laugh particles while she self-corrects. Barbara and her therapist are doing the same exercise as in excerpts 2 and 3 (see section 4.3.1.1). Here, the target word dictated by the computer is the word toujours (Engl. always). Barbara is typing on her keyboard.

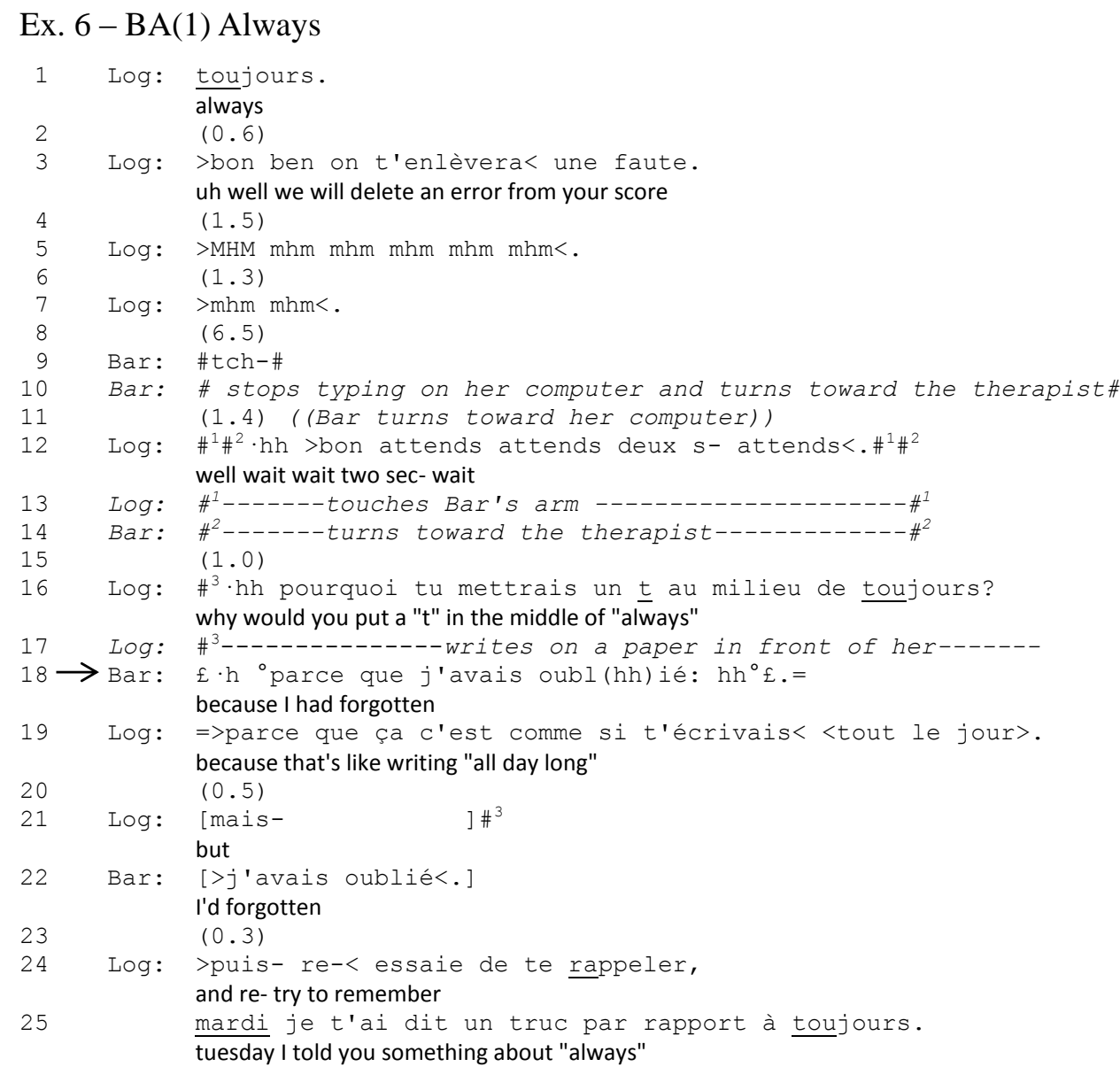

In this excerpt, Barbara is involved in a prolonged correction sequence during which she does not succeed in providing the correct answer, leading the therapist to notify Barbara of a problem with her answer and to invite her to self-correct $(7,12)$. The therapist first repeats the target word (1): she stresses the first syllable of the word, thus displaying it as a potential trouble source. After producing a comment related to a computer problem affecting Barbara's answer to the previous target word (3), the therapist invites Barbara to self-correct by notifying her of a problem in what she is writing $(5,7)$. Since Barbara does not succeed in self-correcting (8-11), the therapist prompts Barbara to stop the exercise $(12,13)$, before asking her why she has put the letter $t$ in the middle of the word toujours (Engl. always) (16). She identifies Barbara's error but without overtly correcting it. In doing that, she offers Barbara an opportunity to self-correct and to write the correct form of the word toujours on the computer (see Seedhouse 2004; Radford 2008 on questions as a way of framing a correction to invite the partner to self-correct; see also Mazeland 1987 on how the teacher initiates students' selfcorrection by analyzing how errors were caused). The therapist thus postpones the other-correction (see MacHoul 1990 on questioning withhold of other-correction). Barbara fills the self-correction slot with a laughing-account (18), explaining that her error is due to a memory failure (see Svennevig 2008 on how an explanation may respond to a repair initiation; see also Antaki 1994 on how the speaker may produce an account after the partner has expressed dissatisfaction with the speaker's previous answer). By producing an account instead of a genuine correction, Barbara uses a "short cut" (Svennevig 2008) that draws attention to the error as caused by a memory failure and not by a lack of spelling ability. By laughing, Barbara responds to the therapist's prompt while inviting her to take the mistake in a light-hearted way. She thus avoids providing the therapist with a slot for an overt correction. And, here too, the therapist neither negatively assesses Barbara's error nor provides the correct form. However, by not laughing, the therapist remains focused on the instructional task. She 
supports Barbara's attempt to find the expected answer by providing explanation (19) and an instructional reminder (24-25).

According to these analyses, in a prolonged correction sequence, the adolescent produces laugh particles that infiltrate his/her response to the therapist's invitation to self-correct. He/she satisfies the therapist's expectations by providing a self-correction while displaying uncertainty regarding its correctness. Laughter allows the adolescent to appeal to the therapist's leniency (Petitjean \& GonzálezMartínez 2015 on classroom data) and to decrease the opportunities for the therapist to make an overt negative evaluation. And, indeed, the therapist does not correct the adolescent's error but invites $\mathrm{him} /$ her to self-correct (exx.4 and 5), providing explanations of how to correct the mistake (exx.5 and 6). However, by not laughing, the therapist displays the pedagogical relevance of the correction, leading the adolescent to focus on learning activities.

\subsubsection{Intermediate conclusions}

Laughter is a very cost-effective resource used by the adolescent to manage prolonged correction sequences initiated by the therapist in speech therapy sessions. During or after the therapist's othercorrection, the adolescent responds by producing standalone laughter. He/she retroactively accomplishes alignment and proactively avoids engaging in justification. After the therapist re-extends her invitation to self-correct several times, the adolescent ends up completing the correction by producing a laughter-infiltrated second pair-part. By laughing, he/she solicits leniency from the therapist, minimizing opportunity for her to produce an other-correction. By inviting the therapist to laugh with him/her at his/her mistake, the adolescent works to suspend the serious implications of his/her mistake (see Glenn 1991), ${ }^{7}$ both at an epistemic level (by treating the lack of epistemic access in a light way) and at a sequential one (by avoiding providing acknowledgment, apologies or justification after the therapist's other-correction, or by minimizing opportunity to be other-corrected after unsuccessful attempts to self-correct). In both cases, the therapist does not join in the adolescent's laughter: she remains focused on the instructional task and shows that she takes the learning activity achieved through the correction seriously.

\subsubsection{Adolescents' shared laughter}

In some cases, the therapist joins in the adolescent's laughter to manage the correction sequence, as in the following excerpts. Barbara has to write the day's date on the therapy logbook while the therapist is preparing a card game. Barbara takes a calendar from the therapist's desk to check the date. On this calendar, the day's date is combined with a word, its definition, an illustration and a question. The French word written on the calendar is acquiescer (Engl. to acquiesce or to agree). Barbara reads the question, which is what is the head movement that we make when we are acquiescing? The therapist provides an answer (1) while shuffling playing cards (2).

\footnotetext{
${ }^{7}$ Glenn shows how laughter may be a way of displaying the non-seriousness of a self-deprecation. In the excerpts analyzed by Glenn, the current speaker produces a laughing negative self-assessment. This is not the case in our data, and we thus prefer to avoid using the term "self-deprecation".
} 
Ex. 7 - BA(1) From the back to the front

1 Log: \#1<on la hausse> de- non on la bouge de haut en bas. we raise it from no we move it from top to bottom

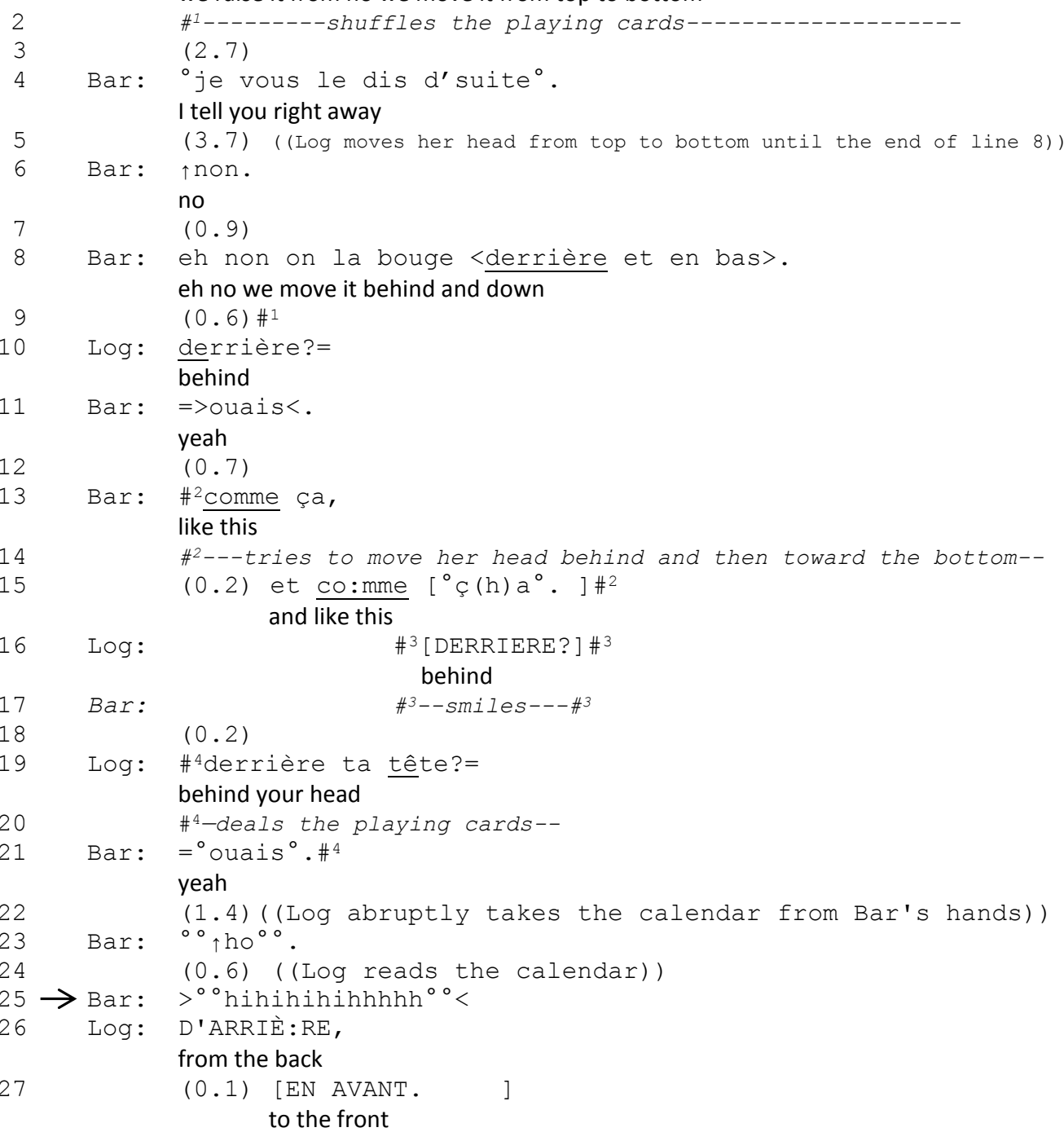

In this excerpt, Barbara and her therapist are involved in a delicate correcting episode. Barbara produces an unmitigated other-correction of the therapist's answer (see the no-tokens in turn-initial 
positions in lines 6 and 8). Since Barbara's formulation is ungrammatical in French $^{8}$, the therapist stops shuffling the playing cards (9) and invites Barbara to self-repair (10). Barbara assertively confirms her formulation (11-15). The therapist disaligns with Barbara by producing an anticipatory (because overlapping) confirmation check (16), urging Barbara to self-correct (see the louder voice in line 16; see also the subsequent repetition of the confirmation check in line 19). Since Barbara does not self-correct yet (21), the therapist takes the calendar from Barbara's hands (22) to check the answer (24). In doing that, she clearly disaligns with Barbara (see the oh-token produced by Barbara in line 23) and announces a potential other-correction, which is produced in lines 26 and 27 (see also the louder voice as a way of displaying the obviousness of the correction). Interestingly, Barbara produces standalone laughter both after the therapist announces and performs the other-correction (respectively lines 25 and 28). As in excerpts 1-3 (see section 4.3.1.1), laughter allows Barbara to downgrade the embarrassment linked to the display of non-knowledge while avoiding elaborating on the therapist's correction. Here however, in contrast to the above-mentioned excerpts, the therapist joins in Barbara's laughter (32) after having assessed Barbara's behavior in a smiling way (30). Note that the expression quelle nouille is not insulting in French, but rather a sweet and affectionate way of evaluating her partner's behavior. Moreover, this expression is inspired by the initial meaning of the word nouille (i.e. noodle, which appears "flabby" after cooking), thus referring to a person who lacks energy. In using this expression with a smile voice, the therapist thus accounts for Barbara's difficulty in selfcorrecting: the therapist more focuses on Barbara's careless mistake than on misreading (see also in line 34 how Barbara affiliates with the therapist when she displays that her difficulty in self-correcting was fake, you waswere afraid uh). By jointly laughing, the participants agree on the non-seriousness of the mistake and orient themselves toward a topic closing, providing opportunity to jointly return to the main activity (playing cards; note here that it is just after having jointly laughed that the therapist starts dealing cards (33) and that Barbara takes hers (35)).

The following excerpt also illustrates the role laughter plays in the management of correction sequences. Barbara and her therapist are discussing a book she is studying at school. Barbara has just said that she did not understand several words in this book. In this excerpt, the therapist does not yet know what kind of book it is (we will hear in the rest of this session that it is Les Fourberies de Scapin by Molière).

\footnotetext{
${ }^{8}$ The expected form in French is bouger la tête d'arrière en avant or bouger la tête de haut en bas (Engl. from the back to the front or from top to bottom).
} 
Ex.8 - BA(2) Dieded

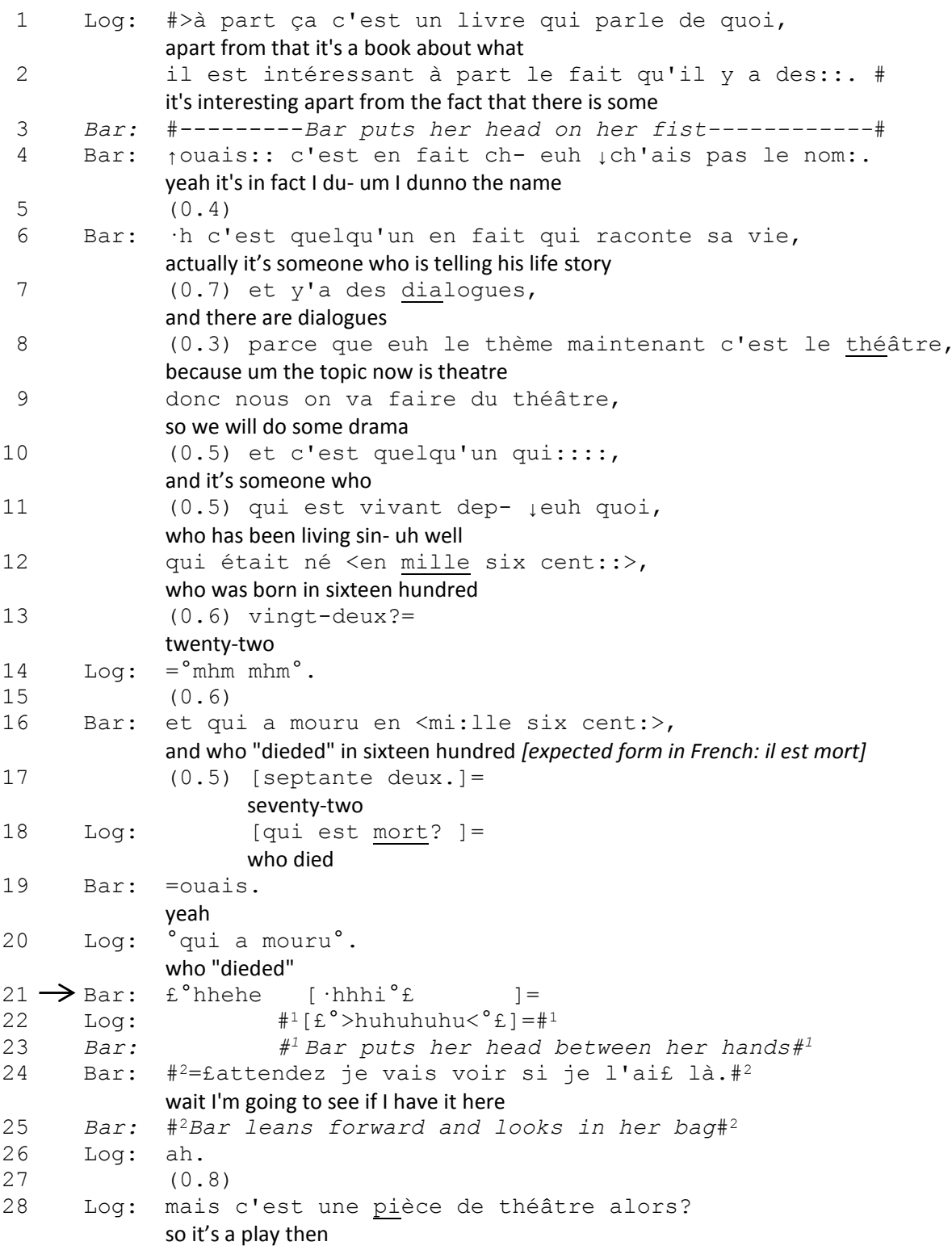

As Barbara is providing the death date of the author, she makes a grammatical error while conjugating the verbal phrase (16), saying il a mouru instead of il est mort (in French, the verbal phrase il a mouru is ungrammatical but very frequent in young children' talk; this is due to a morphologic generalization of verbal declensions). In overlap with Barbara's last TCU, the therapist initiates a correction sequence (18): she provides a mitigated correction by inviting Barbara to confirm the correctness of the substitution she is proposing (il est mort instead of il a mouru). After Barbara has agreed with the therapist's correction and thus completed the correction sequence (19), the therapist repeats the mistake (20). In doing that, the therapist resets the correction sequence (see Drew 1981; Seedhouse 2004; Radford 2008 on how repetition of the partner's error is a way of inviting him/her to produce further elaboration), inviting Barbara to respond ${ }^{9}$. Barbara does not speak but discreetly produces

\footnotetext{
${ }^{9}$ The therapist's repetition of Barbara's mistake could be analyzed as a way of making fun of it (i.e. teasing Barbara), which thus makes relevant subsequent laughter. However, in our view, this analysis is not validated by the shape of the participants' turns. According to Drew (1987), teasing is made recognizable as such through several features: a tease is a responsive action, i.e. a second-pair part that provides an obviously exaggerated
} 
laugh particles (21): she thus responds to the therapist's correction but without elaborating on it. By turning the mistake into a laughable, Barbara downgrades its seriousness and thus minimizes her lack of grammatical knowledge. In line 22, the therapist joins in Barbara's laughter, aligning with and affiliating to Barbara. By producing shared laughter, the participants jointly focus on the fact that the error is not so important here and now. They also orient themselves toward a topic closing (i.e. a wrong morphological declension), providing an opportunity to jointly return to the main activity (i.e. discussing a book). Indeed, after the participants simultaneously stop laughing, Barbara quickly selfselects and closes the correction sequence by initiating another activity (i.e. looking for the book, 24), which is accepted by the therapist (26). After a silence (27), the therapist asks Barbara a new question (28), returning to the topic they had been discussing before the correction sequence, without providing explanation of how the error was caused. By producing shared laughter, the participants thus make accountable the way they organize their in-progress activities into a hierarchy, jointly downgrading the relevance of correcting business within the management of an interactional task. The sequential organization of laughter allows the participants to build a context in which meaning-and-action formation is more important than the use of appropriate linguistic forms (see Seedhouse 2004).

\section{Discussion and conclusion}

Repair management is a central activity in human conduct as it helps maintain inter-subjectivity (Hayashi et al. 2013). This is particularly true for participants whose language impairments may trouble joint understanding and disrupt progression of talk (Milroy and Perkins 1992; Wilkinson 2007; Ridley et al. 2002; Radford 2008; Merrison and Merrison 2005). Our study shows that as a specific type of repair management, correction is also central to therapy settings oriented toward language training, providing opportunities to improve patients' abilities to communicate (see also Radford 2008 on repair). This is especially important when it comes to adolescents suffering from speech and language impairments, who also have to manage correcting activities in classroom interactions (McHoul 1990). Moreover, our analyses show that laughter is a relevant resource in the management of correction sequences in therapy sessions involving adolescents with speech and language impairments, complementing previous studies on laughter in repair with aphasic speakers (Norris and Drummond 1998; Wilkinson 2007).

Following previous studies that show that the lay person laughs more than the representative of the institution (West 1984; Adelswärd 1989; Lavin and Maynard 2001; Haakana 2002), our analyses confirm that adolescents with speech and language impairments initiate more laughs than therapists. We also show that therapists do not join in adolescents' laughter in most cases, corroborating studies on laughter in institutional contexts (Haakana 2001, 2002, Fatigante and Orletti 2013 on medical interactions; Glenn 2013 on job interviews; Lavin and Maynard 2001 on telephone surveys). However, we also show that laughter distribution is not only linked to institutional asymmetry, but also to the activity in which participants are involved: if adolescents do more laughing than therapists, this effect is stronger in correcting activities. Indeed, the sequential organization of laughter (unilateral vs. shared laughter) displays the participants' priority in terms of task management and how they jointly evaluate the importance of correcting in the therapeutic activities. Our analyses thus corroborate previous studies that show how laughter is involved in the management of a specific course of action (see for

version of the previous speaker's turn (e.g. by using extreme case formulations), casting doubt on the credibility of what the tease recipient has just said. It is exaggeration - and contrastiveness with the previous turn - that makes understandable the non-seriousness of the tease. In our excerpt, the therapist's turn is more an initiating action than a responsive one, and does not immediately react to Barbara's previous turn (but rather to Barbara's mistake, produced three turns before). Moreover, by repeating Barbara's mistake with a lower voice, the therapist does not formulate an exaggerated version of Barbara's mistake, but discreetly focuses on it. Note also that the therapist neither laughs nor smiles; yet, in face-to-face interactions, it is mostly the current speaker who laughs first to invite his/her partner to produce subsequent laughter (see Glenn 1991). Drew (1987) also shows that teasing can be sequentially defined through the kind of response produced by the tease recipient: he/she seriously responds to the tease, formulating a po-faced response (e.g. with a no-token in turn-initial position; see also Schegloff 2001). The tease recipient can laugh or smile, but does not always do this. In our excerpt, Barbara does not produce a serious response; she produces only laugh particles. 
instance Vöge 2010 and Holt 2012 on complaints; Osvaldsson 2004 on disagreement; Jefferson 1984 on troubles-telling). However, to our knowledge, there exist no studies showing that laughter is more frequently mobilized in one type of sequence over another in a specific institutional setting (here, therapy sessions).

According to our findings, the adolescent laughs when he/she is involved in a prolonged correction sequence, thus corroborating what Wilkinson (2007) shows on aphasic speakers who laugh after failing to self-correct despite a prolonged effort. However, while Wilkinson focuses on unsuccessful self-repairs of production difficulties, we look at sequences in which the patient does not succeed in providing the expected answer projected by the therapist's request. Our analyses thus complement previous studies on laughter as a resource for managing trouble and delicate moments: while it has been shown that laughter is used to soften problematic actions (Potter and Hepburn 2010; Shaw et al. 2013; Glenn 2013; Petitjean and González-Martínez 2015), to manage disagreement (Osvaldsson 2004; Jacknick 2013) and complaint (Vöge 2010; Holt 2012) or to display resistance to the delicate nature of what is being said or done (Jefferson 1984; Haakana 2001; Vöge 2010; Holt 2012; Fatigante and Orletti 2013), we shed light on how laughter is also an efficient resource for the speaker when his/her partner overtly displays a problem of acceptability regarding the speaker's previous answer. While several studies focus on how laughter is a way of preempting interactional trouble (Potter and Hepburn 2010; Shaw et al. 2013; Petitjean and González-Martínez 2015), we show that laughter is also mobilized when the problem has already impacted the progress of the interaction and persists despite participants' prolonged efforts to resolve it. By laughing at his/her mistake, the adolescent softens the lack of epistemic access that is conveyed by the therapist's correction-initiation (see also Sert and Jacknick 2015 on smiling in L2 classrooms; Benjamin and Mazeland 2013 on correction as a claim of greater authority) while minimizing the serious implications of his/her mistake on the rest of the interaction (see also Schegloff et al. 1977 on joking to downgrade the seriousness of a correction): standalone laughter allows the adolescent to avoid producing acknowledgment or justifications after the therapist's correction; laughter-infiltrated self-correction allows him/her to avoid providing the therapist with a slot for other-correction.

Moreover, we also show that a problem such as a correction may be differently managed according to the interactional unfolding of laughter (unilateral vs. shared laughter): the way in which the error is corrected not only displays epistemic status issues but also how participants index the activity in which they are involved. By not joining in the adolescent's laughter, the therapist remains focused on the business of correction, displaying that the trouble source is too serious to be treated in a light way. Thus, by accomplishing a non-shared laughter, the participants jointly index the business of correction as a central issue for their in-progress therapeutic activity. When the therapist joins in the adolescent's laughter, she retroactively reconfigures the correction trajectory she has initiated (i.e. by displaying that the error is not so serious) and proactively supports a return to an activity that is indexed as the most important in terms of therapeutic targets (i.e. discussion or conversational management). Thus, by accomplishing shared laughter, the participants jointly flag the business of correcting as secondary among their in-progress therapeutic activities. Interestingly, our findings corroborate previous studies on laughter and topic termination (Holt 2010). When the therapist does not join in the adolescent's laughter, she maintains the instructional topic involved in the correction sequence, producing a confirmation check (ex.1), providing explanation (exx.3 and 6), reproaching the partner (ex.2), initiating another self-correction (exx.4 and 5) or continuing the instructional task (exx.1 and 2). When the adolescent and his/her therapist jointly laugh, they close the topic of the correcting episode to return to the task that they thus display as being more relevant (a card game in ex.7; a discussion in ex.8). Mazeland (1987) shows that the placement of the teacher's other-correction is a way of displaying "'more-or-less-focusable' errors". We thus complement this study by showing that the focusability of an error is also displayed by the sequential organization of laughter. By producing unilateral or shared laughter, the adolescent and his/her therapist display what the main task they need to manage is, adapting the role and the importance of the correcting activity to therapeutic purposes and interactional contingencies. Laughter allows participants to reconfigure their priority in terms of language training, moment by moment in the course of interaction: correction might be either the main instructional task (unilateral laughter) or a less relevant resource (shared laughter). By laughing, participants coordinate pedagogical issues (in which the use of appropriate form/reply is expected) to 
interactional business (see also Seedhouse 2004 on the different types of repair in meaning-andfluency vs. form-and-accuracy activities in language classrooms).

By showing how therapists and patients organize laughter to index the instructional role of correction sequences, and how they manage problematic features of making a mistake in terms of epistemic positions, our analyses provide useful therapeutic resources for both therapists and patients. The way in which therapists and patients mobilize laughter shows that the seriousness of an error mostly depends upon the activity in which it occurs, resulting from a moment-by-moment negotiation between participants. Laughter thus allows therapists and patients to "reinvent" what an error is expected to say about the patient's abilities: by jointly laughing, the participants switch from an expertand-novice relationship to co-participants in managing the interaction (see also Nakamura 2008 on repair in informal teacher-student talk). This is particularly relevant for adolescents with speech and language impairments, not only because they are exposed to business of correcting in educational, vocational and professional contexts, but more generally because laughter is one of the resources that may help them to put mistakes into perspective, thus gaining self-confidence while preserving selfesteem.

\section{Acknowledgments}

This study is part of the Sinergia research project Interactional Competences in Institutional Practices: Young People between School and the Workplace (IC-You) funded by the Swiss National Science Foundation (SNSF grant no. CRSII1_136291/1, subproject Interactional competences: Social representations and interactional practices in speech and language therapy). We would hereby like to thank the Faculté des lettres et sciences humaines (University of Neuchâtel) for its financial support. And many thanks to Prof. Adrian Bangerter and Dr. Vassiliki Markaki for their useful feedback, and to Elisabeth Lyman for her careful reading.

\section{References}

Adelswärd, V. 1989. Laughter and Dialogue: The Social Significance of Laughter in Institutional Discourse. Nordic Journal of Linguistics 12(2): 107-136.

Antaki, C. 1994. Explaining and Arguing: The Social Organization of Accounts. London: Sage.

Auburn, T., and C. Pollock. 2013. Laughter and Competence: Children with Severe Autism Using Laughter to Joke and Tease. In Studies of Laughter in Interaction, edited by P. Glenn and E. Holt, 135160. London: Bloomsbury.

Benjamin, T., and H. Mazeland. 2013. Conversation Analysis and Other-Initiated Repair. In The Encyclopedia of Applied Linguistics, edited by Carol A. Chapelle. Blackwell Publishing.

Bonin, F., Campbell, N., and C. Vogel. 2012. Temporal Distribution of Laughter in Conversation. In Proceedings of the Third Interdisciplinary Workshop on Laughter and other Non-Verbal Vocalisations in Speech , 25-26. Dublin, Ireland.

Drew, P. 1981. Adults' Corrections of Children' s Mistakes: A Response to Wells and Montgomery. In Adult-Child Conversation, edited by P. French and M. MacLure, 244-267. London: Croom Helm.

Drew, P. 1987. Po-faced Receipts of Teases. Linguistics 25: 219-253.

Fatigante, M., and F. Orletti. 2013. Laughter and Smiling in a Three-party Medical Encounter: Negotiating Participants' Alignment in Delicate Moments. In Studies of Laughter in Interaction, edited by P. Glenn and E. Holt, 161-183. London: Bloomsbury.

Glenn, P. 1991. Current Speaker Initiation of Two-Party Shared Laughter. Research on Language and Social Interaction 25: 139-162.

Glenn, P. 1995. Laughing at and Laughing with: Negotiations of Participant Alignment Through Conversational Laughter. In Situated Order. Studies in the Social Organization of Talk and Embodied Activities, edited by P. Ten Have and G. Psathas, 43-56. Washington: University Press of America. 
Glenn, P. 2003. Laughter in Interaction. Cambridge: Cambridge University Press.

Glenn, P. 2010. Interviewer Laughs: Shared Laughter and Asymmetries in Employment Interviews. Journal of Pragmatics 42: 1485-1498.

Glenn, P. 2013. Interviewees Volunteered Laughter in Employment Interviews: A Case of 'Nervous' Laughter? In Studies of Laughter in Interaction, edited by P. Glenn and E. Holt, 255-275. London: Bloomsbury.

Glenn, P., and E. Holt, eds. 2013a. Studies of Laughter in Interaction. London: Bloomsbury.

Glenn, P., and E. Holt. 2013b. Introduction. In Studies of Laughter in Interaction, edited by P. Glenn and E. Holt, 2-22. London: Bloomsbury.

Goffman, E. 1956. Embarrassment and Social Organization. American Journal of Sociology 62(3): 264-271.

Haakana, M. 2001. Laughter as a Patient's Resource: Dealing with Delicate Aspects of Medical Interaction. Text 21(1/2): 187-219.

Haakana, M. 2002. Laughter in Medical Interaction: From Quantification to Analysis, and back. Journal of Sociolinguistics 6(2): 207-235.

Hall, J. K. 2007a. Redressing the Roles of Correction and Repair in Research on Second and Foreign Language Learning. The Modern Language Journal 91(iv): 511-526.

Hall, J. K. 2007b. The Devil's in the Details: A Response to Seedhouse. The Modern Language Journal 91(iv): 534-536.

Hayashi, M., Raymond, G., and J. Sidnell. 2013. Conversation Repair and Human Understanding: An Introduction. In Conversation Repair and Human Understanding, edited by M. Hayashi, G. Raymond and J. Sidnell, 1-40. Cambridge: Cambridge University Press.

Hepburn, A., and S. Varney. 2013. Beyond ((Laughter)): Some Notes on Transcription. In Studies of Laughter in Interaction, edited by P. Glenn and E. Holt, 25-38. London: Bloomsbury.

Heritage, J. 2012. The Epistemic Engine: Sequence Organization and Territories of Knowledge. Research on Language and Social Interaction 45(1): 30-52.

Heritage, J., Robinson, J. D., Elliott, M. N., Beckett, M., and M. Wilkes. 2007. Reducing Patients' Unmet Concerns in Primary Care: The Difference One Word Can Make. Journal of General Internal Medicine 22(10): 1429-1433.

Holt, L. 2010. The Last Laugh: Shared Laughter and Topic Termination. Journal of Pragmatics 42: 1513-1525.

Holt, L. 2012. Using Laugh Responses to Defuse Complaints. Research on Language and Social Interaction 45(4): 430-448.

Holt, L. 2013. "There's Many a True Word Said in Jest": Seriousness and Nonseriousness in Interaction. In Studies of Laughter in Interaction, edited by P. Glenn and E. Holt, 69-89. London: Bloomsbury.

Ikeda, K., and D. Bysouth. 2013. Laughter and Turn-Taking: Warranting Next Speakership in Multiparty Interactions. In Studies of Laughter in Interaction, edited by P. Glenn and E. Holt, 39-64. London: Bloomsbury.

Jacknick, C. 2013. 'Cause the Textbook Says...': Laughter and Student Challenges in the ESL Classroom. In Studies of Laughter in Interaction, edited by P. Glenn and E. Holt, 185-200. London: Bloomsbury.

Jefferson, G. 1974. Error Correction as an Interactional Resource. Language in Society 3(2): 181-199.

Jefferson, G. 1984. On the Organization of Laughter in Talk about Troubles. In Structures of Social Action. Studies in Conversation Analysis, edited by J. M. Atkinson and J. Heritage, 79-96. Cambridge: 
Cambridge University Press.

Jefferson, G. 1987. On Exposed and Embedded Correction in Conversation. In Talk and Social Organization, edited by G. Button and J. R. E. Lee, 86-100. Clevedon: Multilingual Matters.

Jefferson, G. 2004. Glossary of Transcript Symbols with an Introduction. In Conversation Analysis: Studies from the First Generation, edited by G. H. Lerner, 13-31. Amsterdam: John Benjamins.

Jefferson, G. 2010. Sometimes a Frog in your Throat is just a Frog in your Throat: Guttural as (sometimes) Laughter-Implicative. Journal of Pragmatics 42: 1476-1484.

Jefferson, G., H. Sacks, and E. Schegloff. 1987. Notes on Laughter in the Pursuit of Intimacy. In Talk and Social Organization, edited by G. Button and J. R. E. Lee, 152-205. Clevedon: Multilingual Matters.

Koshik, I. 2002. Designedly Incomplete Utterances: A Pedagogical Practice for Eliciting Knowledge Displays in Error Correction Sequences. Research on Language and Social Interaction 35(3): 277-309

Lavin, D., and D. W. Maynard. 2001.Standardization vs. Rapport: Respondent Laughter and Interviewer Reaction during Telephone Survey. American Sociological Review 66: 453-479.

MacBeth, D. 2004. The Relevance of Repair for Classroom Correction. Language in Society 33: 703736.

Madden, M.L., Oelschlaeger, M.L., and J.S. Damico. 2002. The conversational Value of Laughter for a Person with Aphasia. Aphasiology 16(12): 1199-1212.

Mazeland, H. 1987. A Short Remark on the Analysis of Institutional Interaction: The Organization of Repair in Lessons. Contribution to the discussion session on "institutional settings", IPrA Conference, Antwerp, August 1987.

McHoul, A. W. 1990. The Organization of Repair in Classroom Talk. Language in Society 19(3): 349377.

Merrison, S., and A. J. Merrison. 2005. Repair in Speech and Language Therapy Interactions: Investigating Pragmatic Language Impairment of Children. Child Language Teaching and Therapy 21(2): 191-211.

Milroy, L., and L. Perkins. 1992. Repair Strategies in Aphasic Discourse; Towards a Collaborative Model. Clinical Linguistics and Phonetics 6 (1/2): 27-40.

Miyachi, K. 2009. Laughter by Japanese Learners of English. SLS 660 Course Paper(2) (Instructor Dr. B. Higgins), www2.hawaii.edu.

Nakamura, I. 2008. Understanding how Teacher and Student Talk with Each Other: An Exploration of how 'Repair' Displays the Co-management of Talk-in-interaction. Language Teaching Research 12 (2): 265-283.

Norris, M. R., and S. S. Drummond. 1998. Communicative Functions of Laughter in Aphasia. J. Neurolinguistics 11(4): 391-402.

Osvaldsson, K. 2004. On Laughter and Disagreement in Multiparty Assessment Talk. Text 24(4): 517545.

Petitjean, C., and E. González-Martínez. 2015. Laughing and Smiling to Manage Trouble in FrenchLanguage Classroom Interaction. Classroom Discourse. DOI: 10.1080/19463014.2015.1010556.

Potter, J., and A. Hepburn. 2010. Putting Aspiration into Words: 'Laugh Particles', Managing Descriptive Trouble and Modulating Action. Journal of Pragmatics 42: 1543-1555.

Potter, R. E., and N. J. Goodman. 1983. The Implementation of Laughter as a Therapy Facilitator with Adult Aphasics. Journal of Communication Disorders 16: 41-48.

Radford, J. 2008. Practices of Other-Initiated Repair in the Classrooms of Children with Specific Speech and Language Difficulties. Applied Linguistics 6: 1-10. 
Radford, J, Ireson, J., and M. Mahon. 2012. The Organization of Repair in SSLD Classroom Discourse: How to Expose the Trouble Source. Journal of Interactional Research in Communication Disorders 3(2).

Ridley, J., Radford, J., and M. Mahon. 2002. How do Teachers Manage Topic and Repair? Child Language Teaching and Therapy 18: 43-58.

Rossano, F., Brown, P., and S. C. Levinson. 2009. Gaze, Questioning, and Culture. In Conversation analysis: Comparative perspectives, edited by J. Sidnell, 187-249. Cambridge: Cambridge University Press.

De Ruiter, J. To appear. Methodological Paradigms in Interaction Research. In Alignment in Communication. Towards a New Theory of Communication, edited by I. Wachsmuth, J. de Ruiter, P. Jaecks and S. Kopp. John Benjamins.

Sacks, H., and E. A. Schegloff. 1979. Two Preferences in the Organization of Reference to Persons in Conversation and Their Interaction. In Everyday Language: Studies in Ethnomethodology, edited by G. Psathas, 15-21. New York: Irvington Publishers.

Sacks, H., Schegloff, E. A., and G. Jefferson. 1974. A Simplest Systematics for the Organization of Turn-taking for Conversation. Language 50: 696-735.

Schegloff, E. 1992. Repair After Next Turn: The Last Structurally Provided Defense of Intersubjectivity in Conversation. The American Journal of Sociology 97(5): 1295-1345.

Schegloff, E. A. 1993. Reflections on Quantification in the Study of Conversation. Research on Language and Social Interaction 26(1): 99-128.

Schegloff, E. A. 2001. Getting Serious: Joke $\rightarrow$ Serious 'no'. Journal of Pragmatics 33: 1947-55.

Schegloff, E. A. 2007. Sequence Organization on Interaction. A primer in Conversation Analysis. Cambridge: Cambridge University Press.

Schegloff, E. A., Jefferson, G., and H. Sacks. 1977. The Preference for Self-Correction in the Organization of Repair in Conversation. Language 53(2): 361-382.

Seedhouse, P. 2004. The Interactional Architecture of the Language Classroom: A Conversation Analysis Perspective. Malden, MA: Blackwell.

Seedhouse, P. 2007. On Ethnomethodological CA and "Linguistic CA": A Reply to Hall. The Modern Language Journal, 91(iv): 527-533.

Sert, O. 2013. 'Epistemic Status Check' as an Interactional Phenomenon in Instructed Learning Settings. Journal of Pragmatics 45: 13-28.

Sert, O., and C. M. Jacknick. 2015. Student Smiles and the Negotiation of Epistemics in L2 Classrooms. Journal of Pragmatics 77: 97-112.

Sert, O., and S. Walsh. 2013. The Interactional Management of Claims of Insufficient Knowledge in English Language Classrooms. Language and Education 27(6): 542-565.

Shaw, C., Hepburn, A., and J. Potter. 2013. Having the Last Laugh: On Post-Completion Laughter Particles. In Studies of Laughter in Interaction, edited by P. Glenn and E. Holt, 91-106. London: Bloomsbury.

Sidnell, J. 2010. Conversation Analysis: An Introduction. London: Wiley-Blackwell.

Steensig, J., and T. Heinemann. 2015. Opening Up Codings? Research on Language and Social Interaction 48(1): 20-25.

Stivers, T. 2015. Coding Social Interaction: A Heretical Approach in Conversation Analysis? Research on Language and Social Interaction 48(1): 1-19.

Svennevig, J. 2008. Trying the Easiest Solution First in Other-initiation of Repair. Journal of Pragmatics 40(2), 333-348. 
Vettin, J., and D. Todt. 2004. Laughter in Conversation: Features of Occurrence and Acoustic Structure. Journal of Nonverbal Behavior 28(2): 93-115.

Vöge, M. 2010. Local Identity Process in Business Meetings Displayed through Laughter in Complaint Sequences. Journal of Pragmatics 42: 1556-1576.

West, C. 1984. Routine Complications. Troubles with Talk between Doctors and Patients. Bloomington: Indiana University Press.

Wilkinson, R. 2007. Managing Linguistic Incompetence as a Delicate Issue in Aphasic Talk-inInteraction: On the Use of Laughter in Prolonged Repair Sequence. Journal of Pragmatics 39(3): 542569.

Wilkinson, R. 2014. Intervening with Conversation Analysis in Speech and Language Therapy: Improving Aphasic Conversation. Research on Language and Social Interaction 47(3): 219-238. 